\title{
Streptocara formosensis Sugimoto, 1930 (Nematoda: Acuariidae) in wild ducks from the southern coast of the Baltic Sea
}

\author{
K. KRÓLACZYK ${ }^{1}$, K. M. KAVETSKA ${ }^{1}$, A. STAPF ${ }^{1}$, E. KALISIŃSKA ${ }^{2}$
}

\begin{abstract}
${ }^{1}$ Laboratory of Biology and Ecology of Parasites,West Pomeranian University of Technology, Judyma Str. 20, 71-466
Szczecin, E-mail: katarzyna.krolaczyk@zut.edu.pl, katarzyna.kavetska@zut.edu.pl, agata.stapf@zut.edu.pl; ${ }^{2}$ Department of Biology and Medical Parasitology, Pomeranian Medical University, Powstańców Wielkopolskich Av. 72, 70-111 Szczecin, Poland, E-mail: ekalist@pum.edu.pl
\end{abstract}

\begin{abstract}
Summary
Although nematofauna of wild ducks in north-western Poland seems to be quite well known, researchers still discover species that are new for the fauna of this region and Europe in general. One of them is Streptocara formosensis Sugimoto, 1930 with distinct ecological specificity (the nematode parasites only ducks wintering in the southern Baltic Sea) and topospecificity (limited to the gizzard). During parasitological research on 1005 wild ducks representing 17 species, 13,333 nematodes were isolated, 360 of which $(2.7 \%)$ were identified as Streptocara formosensis Sugimoto, 1930. The distinguishing feature of this species from other nematodes of the genus Streptocara (Railliet, Henry and Sisoff, 1912) is the absence of a collar and a specific arrangement of deirids at the nerve ring. During the study, the nematodes were located only under the stratum corneum of the gizzard, lying down in the form of characteristic white "springs." This is the first observation of this parasite in the nematofauna of Polish wild birds. The nematode was found in $84(8.35 \%)$ wild ducks representing 7 species: Aythya Marila (Aythyini), Bucephala clangula, Clangula hyemalis, Melanitta nigra, M. fusca, Mergus merganser, Mergellus albellus (Mergini). The highest prevalence $(36.7 \%$ ) occurred in mergansers; the coefficient of dominance showed that $S$. formosensis is a subdominant species in B. clangula, $C$. hyemalis and $M$. merganser, and a rare species in other hosts. The presence of the parasite in only three out of 157 examined A. marila suggests that the greater scaup is only an accidental host for the nematode.
\end{abstract}

Keywords: Nematoda; Streptocara formosensis; Baltic Sea; wild birds

\section{Introduction}

Nematodes of the genus Streptocara (Railliet, Henry and
Sisoff, 1912) parasite many bird species associated with aquatic environments (Baruš et al., 1978; Smogorzewskaja, 1990). They are usually located in the host's gizzard, but in strong invasions they can be found in the esophagus and proventriculus (Kavetska, 2006; Carreno, 2008). The characteristic features of these parasites are the presence of lateral lips at the mouth, and deirids (cervical papillae) variously located in the cephalic segment with $5-9$ teeth. The majority of nematodes from this genus also have collar with edges covered with fine teeth (Gibson, 1968; Carreno, 2008).

In Europe, so far only 5 species of Streptocara nematodes have been found: S. crassicauda (Creplin, 1892) - typical species, S. dogieli Belpolskaja, 1952, S. formosensis Sugimoto, 1930, S. pectinifera (Neuman, 1900) and S. recta (Linstow, 1879) (www.faunaeur.org). In Poland, this genus has been represented only by the typical species (Pojmańska et al., 2007; www.faunaeur.org). However, morphological research of nematodes in the wild birds of northwestern Poland revealed the presence of another species S. formosensis, previously incorrectly identified as Ingliserria cirrohamata (Linstow, 1888) (Smogorzewskaja, 1990; Kavetska, 2005a, 2005b; Kavetska, 2006).

The species was described for the first time by Sugimoto in 1930 as a parasite of the gizzard in Anas platyrhynchos and Cairina moschata (Gibson, 1968). Its presence also was recorded in Estonia, Kaliningrad, Canada, Russia and Italy (www.faunaeur.org). According to Gibson (1968), the most important diagnostic feature of this species is the absence of a collar in the anterior part of the body, a typical structure of other species from this genus, and a specific arrangement of deirids in the area of the nerve ring. The purpose of this study was to present the ecological and morphological characteristics of $S$. formosensis isolated from the digestive tracts of wild ducks wintering on the southern Baltic coast. 


\section{Material and methods}

The material consisted of nematodes isolated from the digestive tracts of 1005 wild ducks (Anseriformes: Anatidae), originating from north-western Poland. The host species were represented by 17 species from eight genera belonging to three different eco-tribes: Anatini $(\mathrm{n}=225)$, Aythyini $(n=413)$ and Mergini $(n=367)$. The studies, conducted in the years 1999 - 2010, included game species in Poland (mallard, teal, tufted duck, and pochard, a total of 471 individuals) and protected species (the remaining duck species, including 534 birds) that were obtained dead from fishing nets. Sex of the examined birds was determined based on external characteristics and gonads, and age determinations were based on the size and patency of bursa Fabricii. The nematodes were fixed and stored in $70 \%$ ethanol, and X-rayed in glycerol or $80 \%$ lactic acid. Morphometric measurements were carried out using a measuring eyepiece on seven selected males and ten females of $S$. formosensis; the quantitative characteristics of the structure of the nematode population were determined using the following parameters: extensiveness, intensity, relative density and domination index (Pojmańska, 1993; Kavetska, 2006).

\section{Results}

From the digestive tracts of the examined hosts, a total of 13,333 nematodes were isolated, $360(2.7 \%)$ of which were identified as $S$. formosensis.
Morphological characterization of S. formosensis

Synonyms: Streptocara somateriae Ryzhikov, 1960 and Paracuaria somateriae (Ryzhikov, 1960) and Leonov et al., 1963.

The examined nematode has a fat body with milky color. It lives under the stratum corneum of the host's gizzard, assuming the shape of a characteristic "spring". Its body surface has distinct transverse striations. The characteristic features of this species are the absence of a collar, and the presence of deirids with three teeth, mostly located near the nerve ring. Deirids with four and five teeth have also been observed; however, it seems to be the result of a fissure in the the middle tooth into several smaller ones, rather than due to great diversity in deirid shapes (Gibson, 1968). Deirid length in males is slightly shorter than their width, while in females deirid width may be two times greater than their length.

Males are clearly shorter than females, with an average length of $7791.4 \mu \mathrm{m}$. Females are almost twice as long, with an average length of $11979.0 \mu \mathrm{m}$. The anterior end of the body in both sexes is the same, equipped with two conical lips (Fig. 1A, B). The buccal capsule is heavily muscled, extends in the distal part, creating a special coating of the muscular pharynx located below. In females, the buccal capsule is a bit deeper than in males (Table 1). The width of the buccal capsule is a characteristic with a great variability, as it ranges from 7.5 to $12.5 \mu \mathrm{m}$ in males and from 12.5 to $20.0 \mu \mathrm{m}$ in females. We also compared the thickness of the wall of the buccal capsule; in females it is slightly thicker $(4.8 \mu \mathrm{m})$ than in males $(3.8 \mu \mathrm{m})$. The width
A.
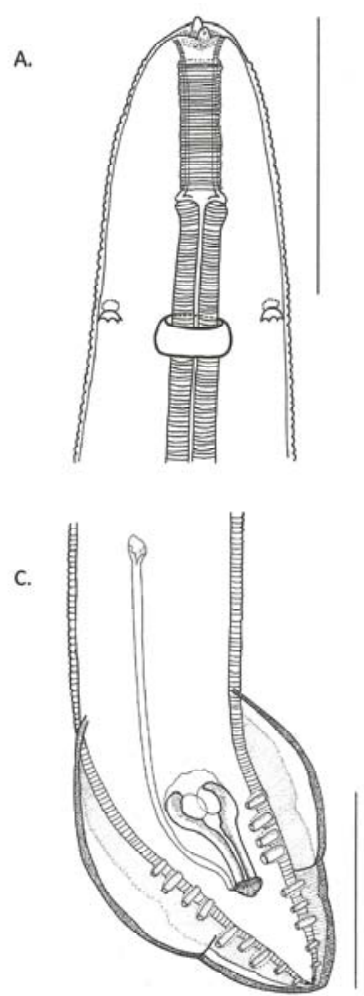

B.

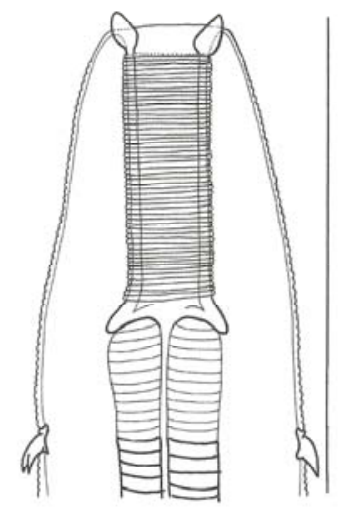

D.

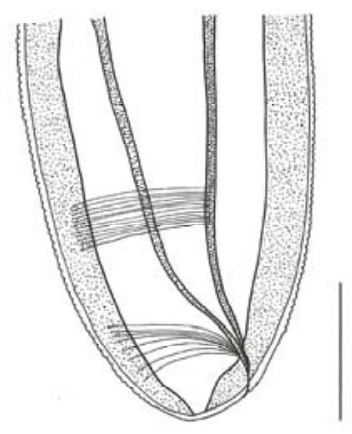

Fig. 1. Morphological characteristic of Streptocara formosensis (Sugimoto 1830); A. anterior end of body S. formosensis, lateral view; B. anterior end of body $S$. formosensis, frontal view; C. posterior end of male's body $S$. fomosensis; D. female's tail S. formosensis. Scale bar: $100 \mu$ m. 


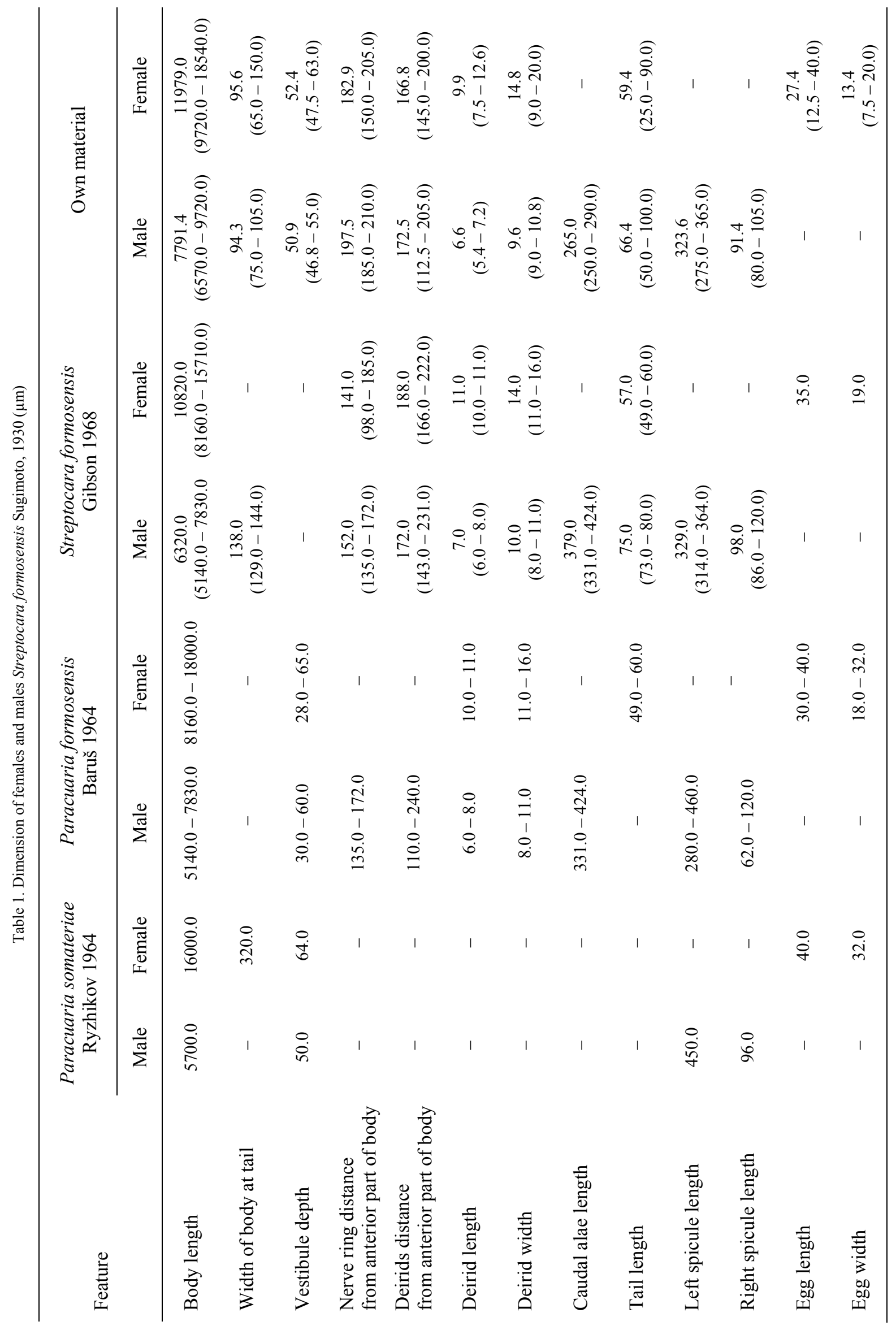


of the body at the buccal capsule in males ranges from 35.0 to $45.0 \mu \mathrm{m}$, while in females it is slightly greater $(40.0-$ $55.0 \mu \mathrm{m})$. In the examined individuals, the pharynx is very long, and the division into the muscular and glandular parts is very poorly marked. The comparison of the sizes of selected structures of $S$. formosensis is shown in Table 1 .

Male $(n=7)$. The posterior end of the male ends with a bursa copulatrix. This structure is surrounded by caudal alae with a mean length of $265 \mu \mathrm{m}$ (Fig. 1C). The copulative organ consists of two spicules, differing in shape and size. The larger spicule is very long $(323.6 \mu \mathrm{m})$ and narrow. Its proximal end has a slight head-shaped extension. In the distal part, the spicule ends sharply and slightly touches the distal part of the small spicule. The small spicule is short and boat-shaped. The proximal part is markedly the widest and tapers to the end; its walls are thick. In the tested preparations, gubernaculum was not visible. Along the sides of the bursa copulatrix there are 10 pairs of caudal papillae, four of which are precloacal pedunculate papillae and 6 postcloacal pairs, the last of which is small and non-pedunculate.

Female $(\mathrm{n}=10)$. The female reproductive organ starts with a vulva located behind the middle of a body. The vulva walls are quite thin and not protruding outside. The vulva opens into a poorly marked, unipolar uterus with a very varied length (from 725.0 to $11600.0 \mu \mathrm{m}$ ). In our preparations, the ovary was not visible. Nematode eggs are oval, measuring $12.5-40.0 \times 7.5-20.0 \mu \mathrm{m}$. The female tail is short and rounded (Figure 1D).

\section{Ecological characteristics}

Under the cuticle of gizzards of $84(8.35 \%)$ ducks out of a total 1005 we found 360 S. formosensis nematodes (Table 2). The parasite was present in the gizzard of 7 host species: Aythya marila (Aythyini), Bucephala clangula, Clangula hyemalis, Melanitta nigra, M. fusca, Mergus merganser, Mergellus albellus (Mergini). Two new parasite-host systems were observed (with the common scoter and velvet scoter). It was found that the only species of the tribe Aythyini with recorded presence of $S$. formosensis was greater scaup. The presence of the parasite in only three out of 157 examined greater scaup suggests that it is only an accidental host for $S$. formosensis. The parasite was not observed in ducks from the tribe Anatini.

The highest prevalence was reported in mergansers $(36.7 \%)$ and lowest in greater scaup $(1.9 \%)$ (Table 2). The high value of this parameter in the smew $(100.0 \%)$ may be due to the fact that only one bird of this species was examined. Most parasites were found in common scoter, slightly less in the velvet scoter (Table 2). The values of relative densities were equal, about one individual of $S$. formosensis in one examined bird. Only in the smew was the value of this indicator higher (3.00).

Based on the dominance coefficient (DC), we found that $S$. formosensis is a subdominant species in the helminthofauna of goldeneye, common mergansers, and long-detailed ducks $(0.1<\mathrm{DC}<1.0)$, while rare in the helminthofauna of greater scaup, common scoter and velvet scoter $(\mathrm{DC}<0.1)$.

Table 2. Ecological characteristic of population Streptocara formosensis Sugimoto, 1930 in investigated ducks

\begin{tabular}{|c|c|c|c|c|c|c|}
\hline \multirow{2}{*}{ Host } & \multicolumn{2}{|c|}{ Prevalence } & \multicolumn{2}{|c|}{ Intensity } & \multirow{2}{*}{$\begin{array}{l}\text { Relative } \\
\text { density }\end{array}$} & \multirow{2}{*}{$\begin{array}{l}\text { Dominance } \\
\text { index }\end{array}$} \\
\hline & $\mathrm{n}$ & $\%$ & range & mean & & \\
\hline \multicolumn{7}{|l|}{ Aythyini (Diving ducks) } \\
\hline Scaup, $n=157$ & 3 & $1.9^{\mathrm{A}, \mathrm{B}, \mathrm{C}}$ & $1-8$ & 4.0 & $0.08^{\mathrm{A}, \mathrm{a}}$ & 0.0015 \\
\hline \multicolumn{7}{|l|}{ Mergini (Sea ducks) } \\
\hline Goldeneye, $n=32$ & 7 & $21.9^{\mathrm{A}, \mathrm{D}, \mathrm{a}}$ & $1-12$ & 3.9 & 0.84 & 0.1846 \\
\hline Long-tailed duck, $\mathrm{n}=112$ & 41 & $36.6^{\mathrm{B}, \mathrm{E}, \mathrm{F}}$ & $1-12$ & 3.7 & $1.35^{\mathrm{A}, \mathrm{B}}$ & 0.4935 \\
\hline Common scoter, $\mathrm{n}=108$ & 6 & $5.5^{\mathrm{D}, \mathrm{E}, \mathrm{G}}$ & $1-47$ & 11.2 & $0.62^{\mathrm{B}}$ & 0.0345 \\
\hline Velvet scoter, $\mathrm{n}=48$ & 4 & $8.3^{\mathrm{a}, \mathrm{F}, \mathrm{H}}$ & $1-29$ & 8.3 & 0.69 & 0.0573 \\
\hline Smew, $\mathrm{n}=1$ & 1 & 100.0 & 3 & 3.0 & 3.00 & 3.0000 \\
\hline Goosander, $n=60$ & 22 & $36.7^{\mathrm{C}, \mathrm{G}, \mathrm{H}}$ & $1-14$ & 3.0 & $1.12^{\mathrm{a}}$ & 0.4094 \\
\hline
\end{tabular}

Statistically significant differences between the data in the column are marked with small letters when $\mathrm{p}<0.05$; and with capital letters when $\mathrm{p}<0.01$ 


\section{Discussion}

Although the systematic position of $S$. formosensis has been amended several times over several decades, it still raises many doubts. This is due mainly to the morphology of the anterior part of the body of this parasite, which according to some authors, is characteristic for the genus Streptocara (Gibson, 1968; Wong \& Anderson, 1982), or Paracuaria (Baruš, 1978; Borgsteede et al., 2005). S. formosensis was first described by Sugimoto (1930) as a parasite of the gizzard of Anas platyrhynchos and Cairina moschata (Gibson, 1968). In 1960 Ryzhikov isolated this nematode from the gizzard of Somateria mollissima and called them Streptocara somateriae, and in 1964 together with Kurochkin (Kurochkin \& Ryzhikov, 1964) transferred them to the genus Paracuaria. On the other hand, Baruš et al. (1978) described the nematode as a new species isolated from the gizzards of birds from the genera Melanitta, Somateria, Aythya, and named it Paracuaria formosensis. Finally, Gibson (1968), in his revision of the genus Streptocara, considered Streptocara somateriae and Paracuaria formosensis as synonymous with Streptocara formosensis. The author analyzed the morphology of nematodes isolated from birds from the orders Anseriformes and Podicipediformes, and drew attention to several features that distinguish this parasite from the genus Paracuaria: the anterior part of the body without a collar and with a simpler construction, subterminal position of anus in females, characteristic shape and arrangement of deirids in both sexes, and a much shorter buccal capsule (Gibson, 1968). According to the author, these characteristics eventually speak for the affiliation of this species to the genus Streptocara. The transfer of $P$. formosensis to the genus Streptocara is also advocated by Wong and Anderson (1982) in their rediscription of Paracuaria adunca isolated from Larus delawarensis from Canada.

In this study, nematodes were identified as $S$. formosensis based on two crucial attributes specified by Gibson (1968): the absence of a collar around the mouth and the presence of deirids located in the vicinity of the ring nerve. Baruš et al. (1978), a description of $P$. formosensis noticed that at the anterior end of the body, both in males and females, there are poorly visible cordons extending from the mouth, characteristic for the genus Paracuaria. In our study, no such structure was observed. Comparing the descriptions of the posterior end of the male in this study and the aforementioned author, we observed differences in the length of the caudal alae, and the presence of a small tooth on the ventral side of a small spicule. The other sizes and descriptions of the structures are similar (Baruš et al., 1978). Another description of S. somateriae was presented Ryzhikov (1960). The author reported that in the cephalic end of the body there is no serrated collar, and proximal papillae with crescent-shaped teeth can be found at a distance equal to the double length of the buccal capsule. Nematodes analyzed in this paper also had no collar. However, in both sexes deirids were located at a much greater distance from the anterior end than observed by Ryzhikov (1960). Other sizes of structures were similar to those reported by Ryzhikov (1960), except for the width of the parasite's body, which is much smaller in our study. Moreover, Ryzhikov (1960) showed that the longer spicule in the male has a length of only $45 \mu \mathrm{m}$. Four years later, Kurochkin and Ryzhikov (1964) presented the description of $P$. somateriae with a correction of a mistake concerning the length of the greater spicule, giving the proper dimension $450 \mu \mathrm{m}$. In our material, a large spicule is a bit shorter than the measurement in the article of Kurochkin and Ryzhikov from 1964 (Table 1).

The most detailed description of $S$. formosensis was given by Gibson (1968). The author concludes, inter alia, that individuals of this species have three deirids whose width and distance from the posterior end of the body is the same as that presented in this paper. The author also noted that the long spicule is closed within a $15 \mu \mathrm{m}$ wide vagina. He also observed that the distal end of the longer spicule is inserted into the edge of the small spicule. In our material we did not observe a vagina closely surrounding the large spicule - it may be associated with the quality of preparations, although all the sizes of the structures of the studied nematode had very similar values to those presented by Gibson (1968).

Our results suggest the affiliation of the examined nematodes to the genus Streptocara. The comparison of measurements of the internal structures performed in this work with measurements by other authors shows significant similarities. They confirm the assumption by Gibson (1968) that $P$. formosensis and $S$. somateriae are synonyms of $S$. formosensis.

Available literature does not provide any specific data on the ecology of this nematode. Borgsteede et al (2005) examined the helminthofauna of $S$. mollissima from the Netherlands, and in two out of 7 birds they recorded in the presence of $P$. formosensis (28.6\%). In our study, $S$. formosensis was not recorded in this host species. This may be associated with the small number (only 4) of this species in our survey.

In this study, the highest prevalence of $S$. formosensis was observed in Mergini, living in northeastern Asia. Most of these birds spend winter on the southern Baltic coast. The absence of this nematode in ducks from the tribe Anatini and only in $0.97 \%$ Aythyini shows that these birds are not specific finals hosts for this helminth. The occurrence of this parasite in greater scaup can be explained by the partial overlap of its nesting grounds with those of sea ducks, which facilitates contact with the intermediate host of the examined nematode.

The obtained data indicate that $S$. formosensis is a species that is brought to Europe from other areas and does not complete its life cycle here.

\section{Acknowledgement}

The research was partly funded by Ministry of Science and Higher Education (PhD project: N N303 569338). 


\section{References}

BAruš, V., Sergeeva, T. P., Sonin, M. D., Ryzhikov, K. M. (1978): Helminth of Fish-Eating Birds of the Palaearctic Region I Nematoda. Moskwa/Praga, Academia Praha, pp. $147-151$

Borgsteede, F. H. M., Okulewicz, A., Zoun, P. E. F., OKULEWICZ, J. (2005): The gastrointestinal helminth fauna of the eider duck (Somateria mollissima L.) in the Netherlands. Helminthologia, 42: 83 - 87

CARreno, R. A. (2008): Dispharynx, Echinuria and Streptocara. In: AtKinson, T. C., Thomas, N. C., Hunter, D. B. (Eds) Parasitic diseases of wild Birds. Ames, Iowa, USA, Wiley-Blackwell, pp. 337 - 339

GIBSON, G. G. (1968): Species composition of the genus Streptocara Railliet et al., 1912 and the occurrence of these avian nematodes (Acuariidae) on the Canadian Pacific coast. Can. J. Zool., 46: $629-645$

KAVETSKA, K. M. (2005a): Nematode fauna of the Mergini (Antatinae) ducks in North-Western of Poland. Vest. Zool., Suppl., 19: $160-161$

KAVETSKA, K. M. (2005b): Nicienie przewodu pokarmowego grążyc (Aythyini) z terenu Pomorza Zachodniego. Wiad. Parazytol., 51: 157 - 163 (In Polish)

KAVETSKA, K. M. (2006): Biological and ecological background of nematode fauna structure formation in the ali- mentary tracts of wild Anatinae ducks in north-western Poland. Habilitation thesis, Poland, Szczecin: Academy of Agriculture (In Polish)

KuROCHKIN, Y. V., RYZHIKOV, K. M. (1964): On the species composition of the genus Paracuaria Rao, 1951 (Nematoda: Spirurata). Sbor. Parazit. Rab. Tr. Astrakhan. Zapov., 9: 182 - 191 (In Russian)

POJMAŃSKA, T. (1993): The review of ecological terms used contemporarily in parasitology. Wiad. Parazytol., 39: 285 - 297 (In Polish)

Pojmańska, T., Niewiadomska, K., OKulewicz, A. (2007): Parasitic helminths in Poland Species, Hosts, Blans Pages. Warszawa, Poland, Polish Parasitological Society, pp. 138 - 156 (In Polish)

RYZHIKOV, K. M. (1960): On the helminthofauna of the king eider. Trudy Gelmintol. Lab., Akademia Nauk SSSR, 10: 173 - 187 (In Russian)

SMOGORZEWSKAJA, L. A. (1990): Fauna Ukrainy. Nematody. Acuarioidea. Akademia Nauk Ukrainskoj SSR, Kiev Naukowa Dumka, 32: 124 - 125 (In Russian)

Wong, P. L., ANDERSON, R. C. (1982): Redescription of Paracuaria adunca (Creplin, 1846) (Nematoda: Acuarioidea) from Larus delawarensis Ord (Laridae). Can. J. Zool., 60: $175-179$

Fauna Europaea Database (2010) http://www.faunaeur.org 